\title{
SPLINTER HILl RESERVE, AN IN-DEPTH LOOK
}

BRIAN BARNES • ICPS Conservation Director • brian@carnivorousplants.org

Keywords: Splinter Hill Reserve, Conservation

I arrived in beautiful Baldwin County, Alabama on the misty morning of May 8th, 2009. Heavy blankets of fog cascaded their way across the vast bog expanses and the humidity was literally thick enough to cut with a knife. And that was when I saw them...Rolling seas of snowy-white, barely discernable through the drifting clouds, as if they were peeking through from some sort of magical dreamland. This was it. This was what I had just driven nine hours for. I'd seen photos through the years of massive ponds of Sarracenia leucophylla, but only was familiar with the ever-dwindling smaller colonies of the aforementioned that existed in the Florida Panhandle. But never anything like this. This was serious "Leuco" country and I knew it. (see Back Cover)

The hair stood on my neck as I envisioned what the next three days in paradise was gonna be like!

I looked forward to meeting with Keith Tassin of The Nature Conservancy (TNC) and interviewing him on video. As Director of Conservation for the ICPS, I was here on a mission. The ICPS has been a frequent supporter of TNC's wonderful efforts at maintaining and guarding this pristine environment and I was here to see what bang we were getting for our buck. From what I saw, we definitely had never wasted one dime of it! I was very impressed by what I saw.

As I pulled up to our rendezvous point, I couldn't stand it any longer! Burdened with loads of camera gear, I just had to get a few shots in as the fog was beginning to lift and the lighting was perfect. Finishing my last sips of coffee, I stared in sheer amazement at the incredible diversity amongst the massive Sarracenia

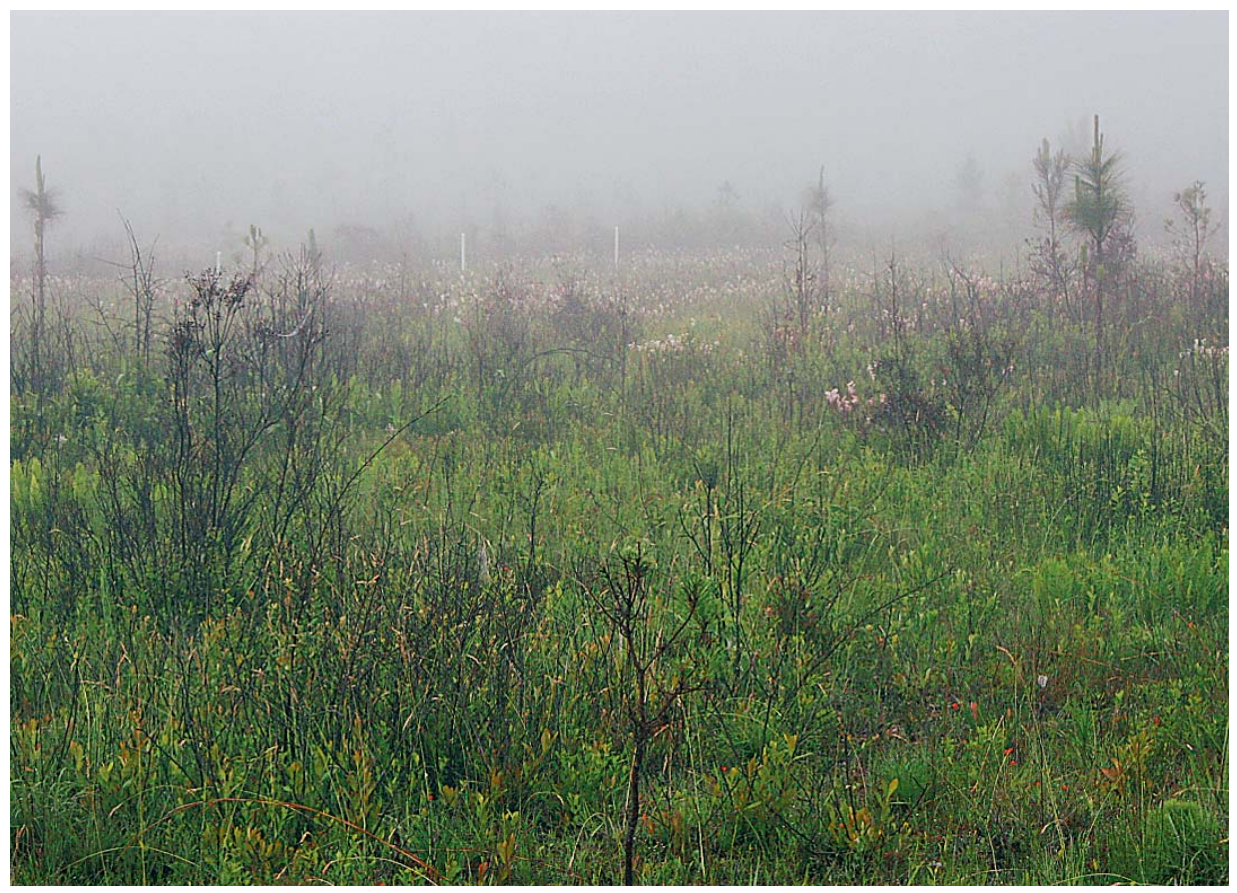

Figure 1: Beautiful Splinter Hill Reserve in Alabama, USA. Rain collection gauges can be seen in the left background as part of University of Southern Alabama's genetics research project. All photos by Brian Barnes. 
colonies. Beautiful stands of Sarracenia leucophylla, Sarracenia rubra subsp. wherryi, Sarracenia psittacina and Sarracenia rosea all were existing in perfect harmony and there were very complex hybrids between all four mentioned species present. Upon seeing this, I truly must say I question the species purity of most of the Sarracenia in my own collection! Many of the populations present, showed some sort of genetic tainting of species purity. I've mainly been studying Sarracenia minor populations in central Florida over the last several years as a personal preference, because they are hundreds of miles from any other Sarracenia species, and species purity is most definitely maintained in those colonies.

Surprisingly enough, there were a few hybrids with blatant Sarracenia flava characteristics, although a full day's search revealed no $S$. flava stands present. Quite clearly, S. flava were here at one time and their obvious influence can be plainly seen in the Figures. I was eager to begin the day's filming. Keith Tassin of TNC gave me the "Tour de Grande" on the first day and I was very impressed with his knowledge of the area. Through the much needed prescribed fires that the ICPS helps to fund with the generous donations from its cherished members, Splinter Hill Reserve has remained unspoiled and is truly one of the finest Sarracenia locations in the U.S. And now, it was time to get to work!

I began walking amongst the tall colonies of Sarracenia that were so thick that my pant legs smelled like nectar afterwards. My goal was to try my very best to film an up close and personal encounter with this enchanted place in order to raise public awareness, which also leads to conservation. But I am also well aware that there must be a fine balance between the two. I tried to capture every possible natural sound of the birds and insects that inhabit this magical land. Sometimes this required lying in the mud in order to get up close and personal, but I didn't mind. It was all for the future well-being of our beloved CP! I tried my best to bring the actual full bog experience to people around the world, who may never get a chance to actually see the magnificent wonder of this place.

The ICPS has also funded genetic research going on at Splinter Hill by the University of Southern Alabama. While I was there, I saw the plots, markers and water collectors that were set up for gathering data. Unfortunately, very foul weather in the region shortly after my visit delayed the end results of this fine work for a bit. But I am in constant touch with the U. of S.A. and will be reporting the results to the ICPS and our members first-hand, as soon as they are complete.

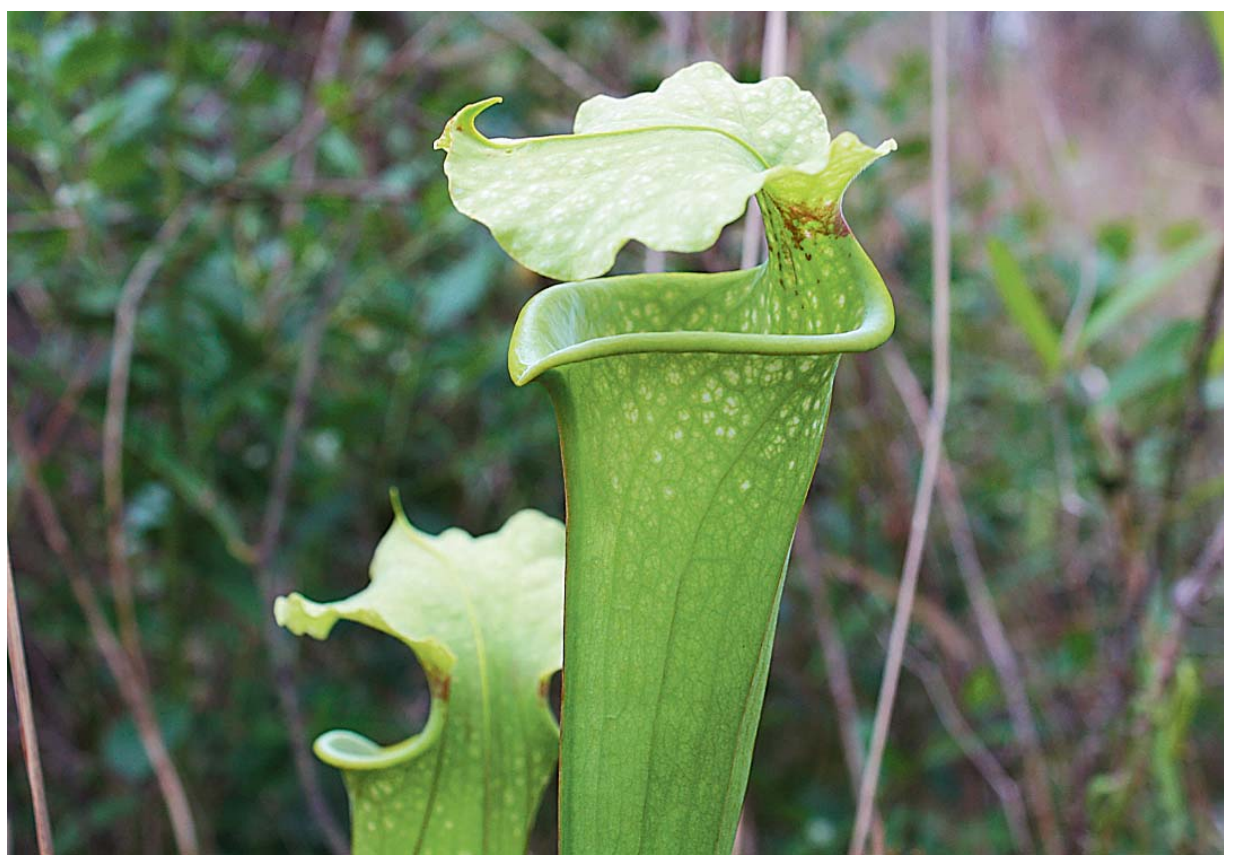

Figure 2: A fabulous Sarracenia flava x leucophylla hybrid. Photo by Brian Barnes. 
For the last two days, I flew solo. Upon our departure, I graciously thanked Keith Tassin and TNC for their expertise and unbeatable hospitality during my filming and research. The remaining days flew by way too fast. I was in the field 12 hours a day and loving every minute. It was almost like being in another world. A world full of hungry open mouths swaying gently in the breeze, waiting to be fed.

On the day of my leaving, I was still in a daze of amazement from the diversity amongst the Sarracenia colonies and the pristine conditions of the bogs. I wish I had more time, but there were more fish to fry, so to speak. I was meeting with Mark Todd of the North American Sarracenia Conservancy (NASC) and Serge Grondin in the magnificent Florida Panhandle to aid in a CP rescue from a condemned site in Bay County. Many plants were rescued during this trip and full video documentation of the ICPS/NASC CP Rescue and the Splinter Hill Experience can be viewed in HD via the link on the ICPS homepage under "ICPS Projects"

After the CP rescue operation was finished, it was time to show some of my old familiar CP haunts to Mark and Serge in the Florida Panhandle. So once again with camera bags in hand, we were off!

Stay tuned for details in the next wonderful CPN issue! Until then, Happy Growing!

Brian Barnes, ICPS Director of Conservation.

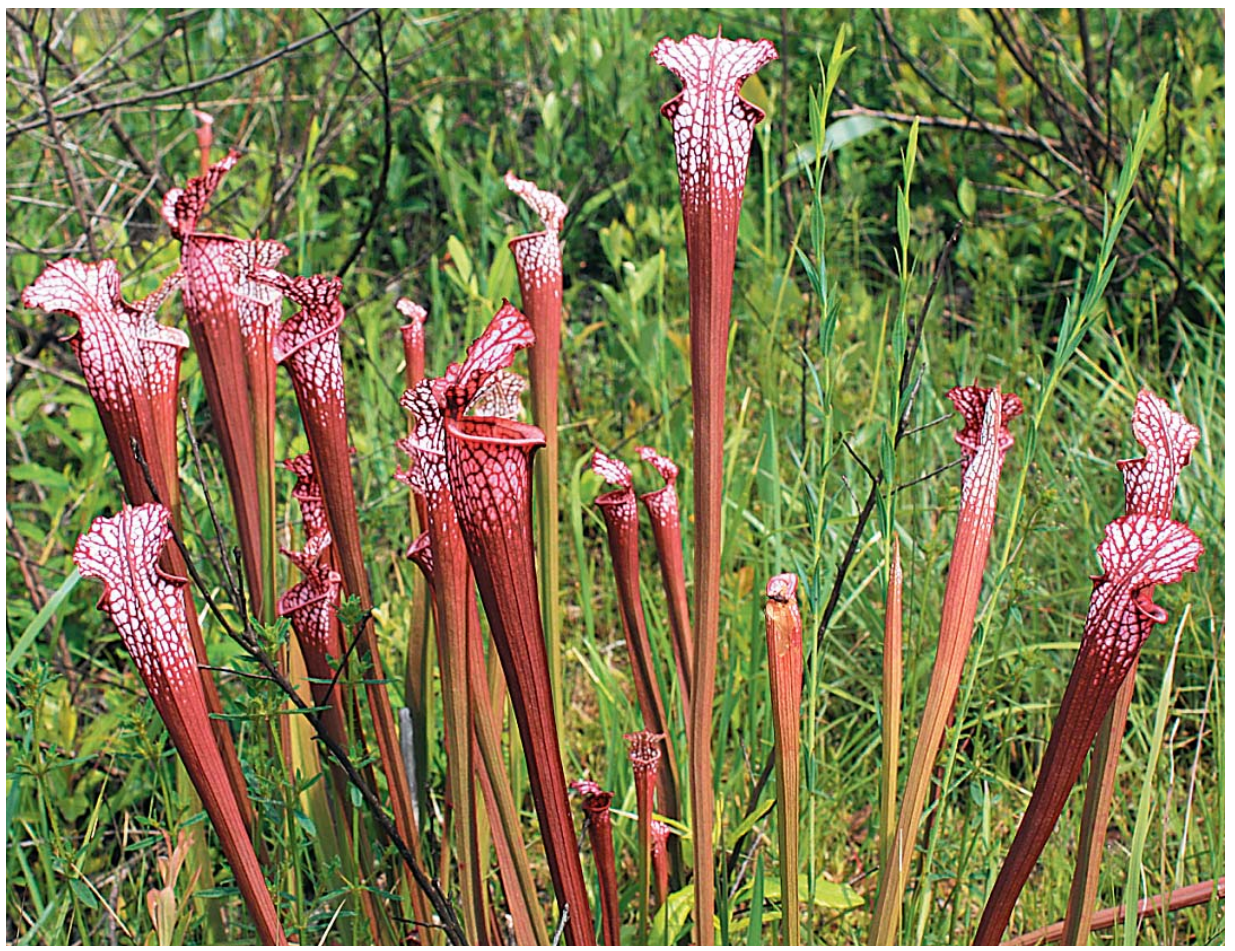

Figure 3: A rare red form of Sarracenia leucophylla. Photo by Brian Barnes. 


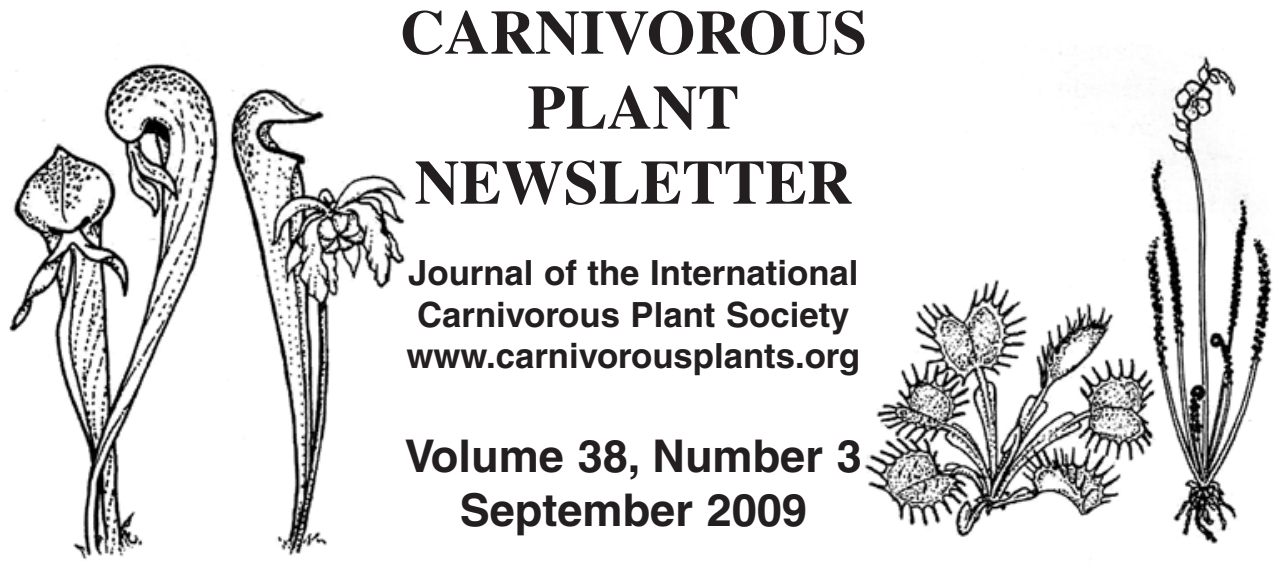

Front Cover: Grasshopper caught in Drosophylum Iusitanicum. Photo by Chiara di Biase. Article on page 88.

Back Cover: Massive stands of Sarracenia leucophylla at Splinter Hill Reserve. Note variation amongst pitchers. Photo by Brian Barnes. Article on page 68.

Carnivorous Plant Newsletter is dedicated to spreading knowledge and news related to carnivorous plants. Reader contributions are essential for this mission to be successful. Do not hesitate to contact the editors with information about your plants, conservation projects, field trips, or noteworthy events. Contributors should review the "Instructions to Authors" printed in the March issue of each year. Advertisers should contact the editors. Views expressed in this publication are those of the authors, not the editorial staff.

All correspondence regarding dues, address changes and missing issues should be sent to the Membership Coordinator at the ICPS. Do not send such correspondence to the editors. Checks for subscriptions should be made to the ICPS in US funds. Dues for 2009 are $\$ 35$ for the first year of membership; renewals are $\$ 30$ per year.

\author{
ICPS, Inc. \\ PMB 322 \\ 1564-A Fitzgerald Drive \\ Pinole, CA 94564-2229, USA \\ icps@ carnivorousplants.org
}

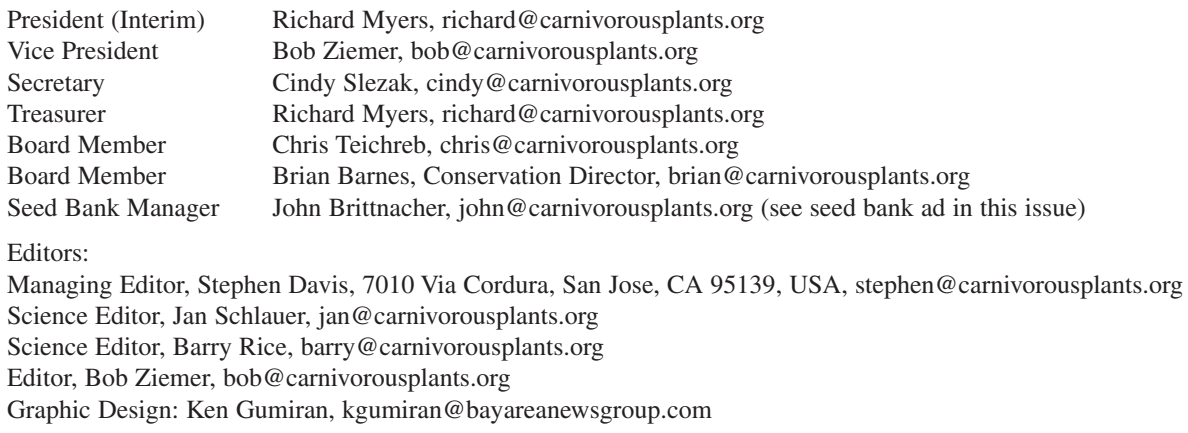

Date of effective publication of the June 2009 issue of Carnivorous Plant Newsletter: 29 June 2009.

The ICPS is the International Cultivar Registration Authority (ICRA) for cultivated carnivorous plants according to The International Code For The Nomenclature of Cultivated Plants. Send relevant correspondence to the ICPS, Inc.

PUBLISHER: ICPS, Inc., Pinole, California. Published quarterly with one volume annually. Graphic Production: Ken Gumiran, 2640 Shadelands Drive, Walnut Creek, CA. Printer: Kandid Litho. Logo and masthead art: Paul Milauskas. Dues for 2009 are $\$ 35$ for the first year of membership; renewals are $\$ 30$ per year. (C) 2009 Carnivorous Plant Newsletter. All rights reserved. ISSN \#0190-9215 


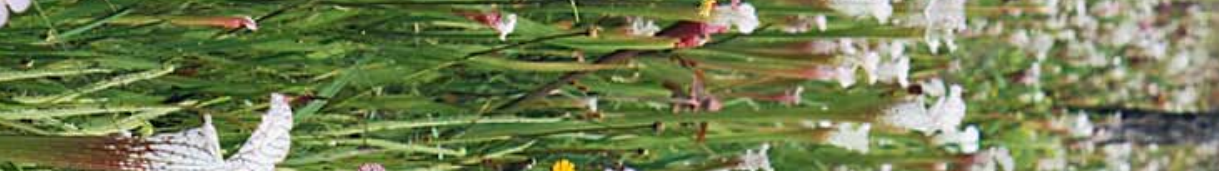

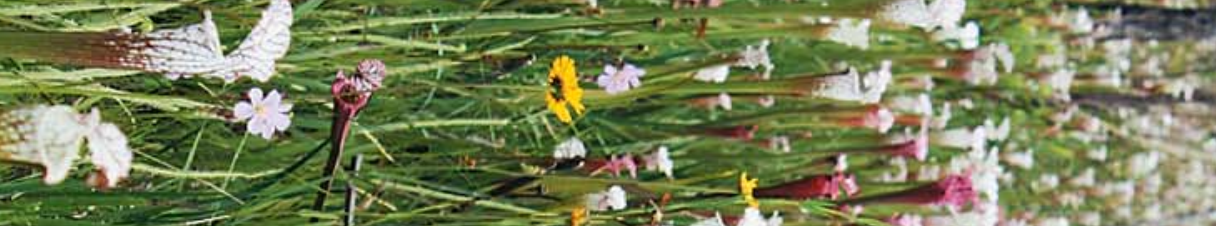
1. $x^{2}$ -

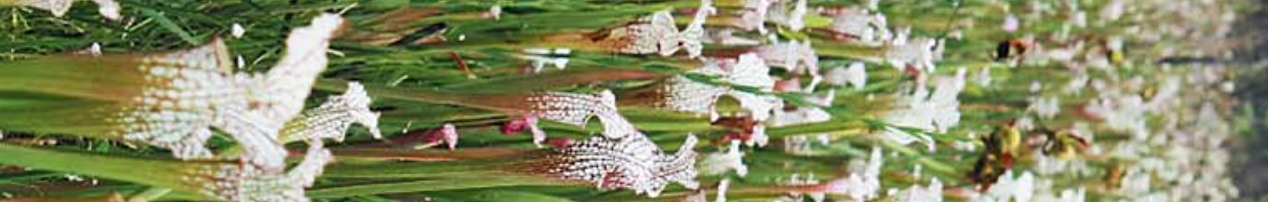

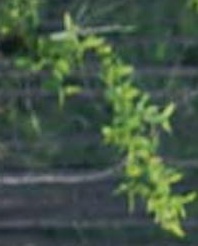

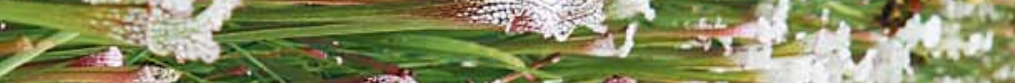

intist mas

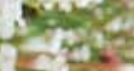
$3 \times 28$

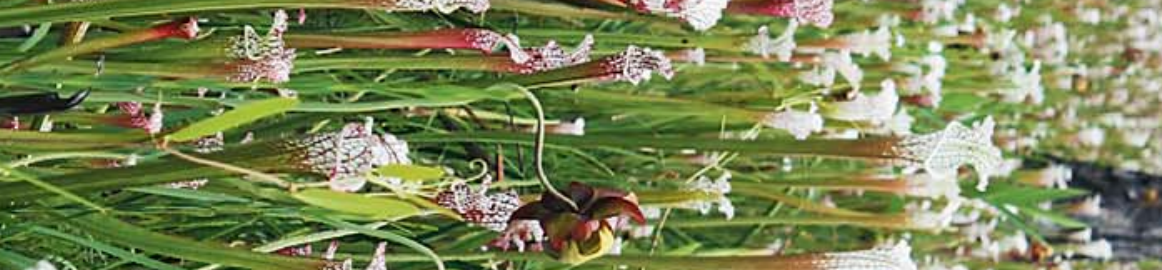

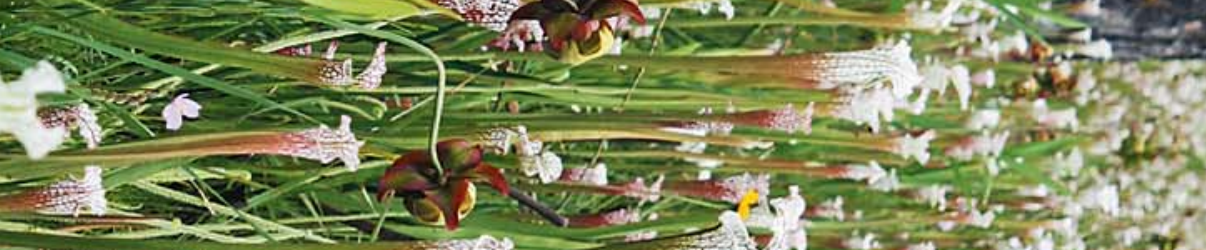

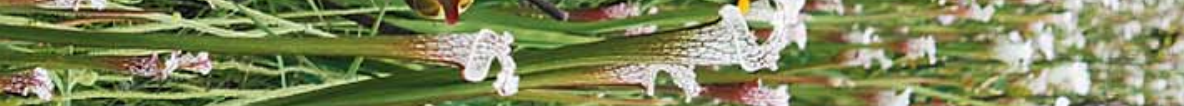

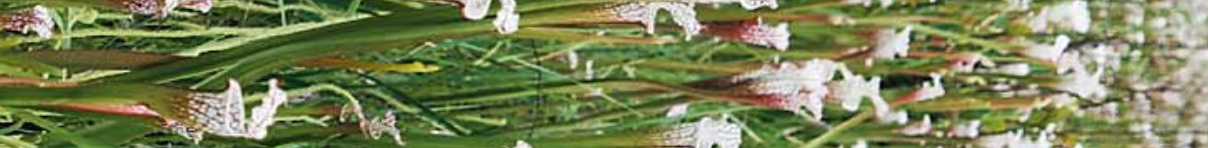

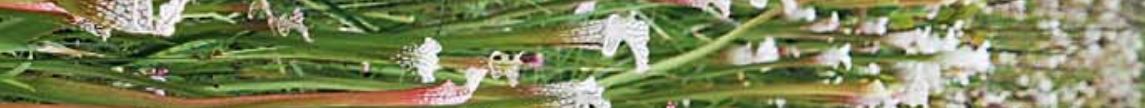
mas.

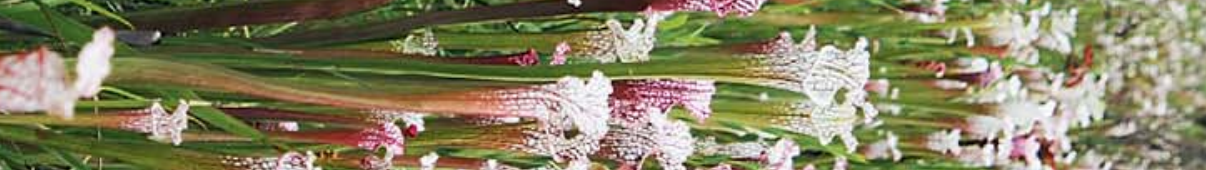
3.

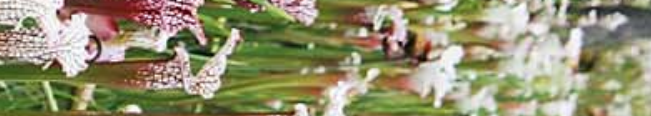

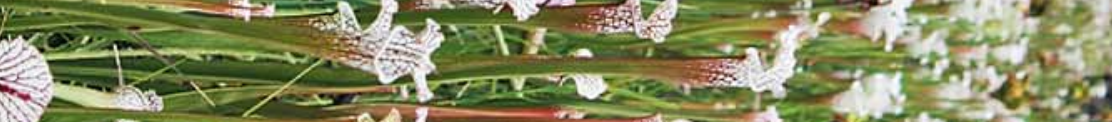

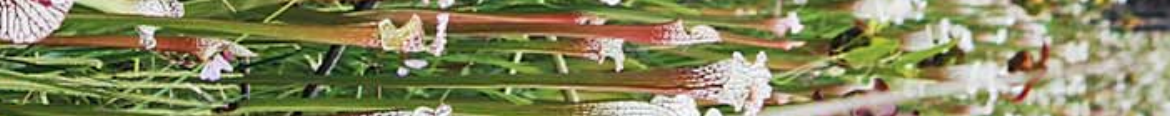

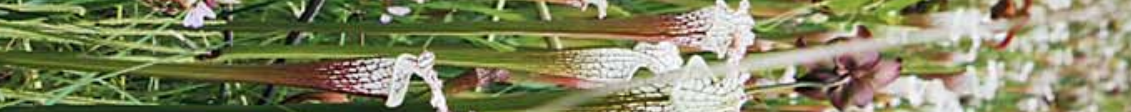

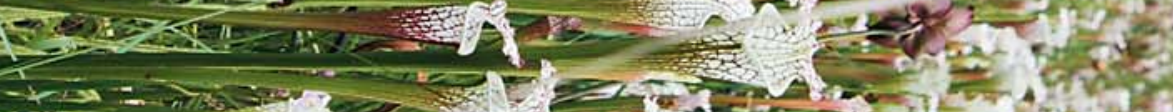

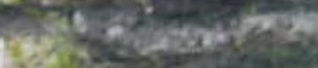

